\title{
Reinstatement of Nepenthes hemsleyana (Nepenthaceae), an endemic pitcher plant from Borneo, with a discussion of associated Nepenthes taxa
}

\author{
M. Scharmann ${ }^{1}$, T.U. Grafe ${ }^{2}$
}

Key words

Borneo

endemic

Malesia

Nepenthes

pitcher plant

reinstatement

taxonomy
Abstract Recently, N. baramensis and N. rafflesiana var. subglandulosa were described from Borneo as new taxa closely related to $N$. rafflesiana. However, comparison of new collections made in Borneo with $N$. baramensis and $N$. rafflesiana var. subglandulosa indicated a synonymy. Furthermore, they were identical to $N$. hemsleyana, an older taxon formerly treated as synonym of $N$. rafflesiana. Acknowledging the taxonomic differences to $N$. rafflesiana, the name $N$. hemsleyana is reinstated following the priority rule. New evidence is presented that strengthens the interpretation to split $N$. rafflesiana and $N$. hemsleyana.

Published on 8 May 2013

\section{INTRODUCTION}

The Asian pitcher plant genus Nepenthes has seen a remarkable increase in species number over the last few decades (Jebb \& Cheek 1997, Cheek \& Jebb 2001), and our understanding of their physiology and ecology has grown substantially. This is due to ongoing exploration of remote areas and historical collections, and the steadily rising academic interest. The species we present here was first collected 136 years ago, but has been considered a synonym of the more common $N$. rafflesiana Jack for most of the time since. However, over the years, many researchers have independently noted two rather different kinds of plant going under that name. We will outline the botanical history and current opinion on this long neglected Nepenthes species, which was strongly influenced by the consideration of only recently established ecological context (see also Clarke \& Moran 2011).

The first collection of the species was made by Frederick Burbidge, the renowned Victorian plant hunter who travelled Borneo and the Sulu Archipelago in 1877-1878. Among many other botanical gems, he introduced the giant pitcher plant $N$. rajah Hook.f. In September 1877, on his first visit to Borneo, he left Labuan Island and sailed up the Lawas River (present-day northern Sarawak, Malaysia; Burbidge 1880). He stayed in "Meringit, a Kadyan settlement at the head of the Meropok branch [of the Lawas River]". On an excursion, he and his party "followed one little stream for about two miles, and reached a rocky hill about five hundred feet high [...]". On this hill they found five types of pitcher plant: $N$. gracilis Korth., $N$. hirsuta Hook.f., N. rafflesiana, N. veitchii Hook.f., "and the large-urned variety of the last named, known as 'glaberrima'". He reports the collection of an undetermined number of specimens from

\footnotetext{
${ }^{1}$ Department of Animal Ecology and Tropical Biology, University of Würzburg, Am Hubland, 97074 Würzburg, Germany; Department of Zoology, University of Cambridge, Downing Street, Cambridge CB2 3EJ, UK; Institute of Integrative Biology, ETH Zurich, Universitätsstrasse 16, CH-8092 Zurich, Switzerland;

corresponding author e-mail: mathias.scharmann@env.ethz.ch.

2 Department of Biology, Universiti Brunei Darussalam, Tungku Link, Gadong 1410, Brunei Darussalam.
}

this site, but not from any other sites on his only Lawas trip (Burbridge 1880). Unfortunately, Burbidge assigned no collector numbers, and material from his Borneo voyage was later distributed to Kew (K), the British Museum of Natural History (BM), Saint Petersburg (LE), Bogor (BO), Singapore (SING) and Edinburgh (E) (Van Steenis-Kruseman \& Van Welzen 1950 onwards); we use standard herbarium acronyms following Index Herbariorum (Thiers, continually updated). Note that the name N. rafflesiana "glaberrima" as used by Burbidge to refer to a distinct kind of pitcher plant was informal. Nothing suggests a connection to N. rafflesiana var. glaberrima Hook.f., which was described prior to Burbidge's voyage but lacks specimens and mention of pitcher characteristics (Hooker 1873).

Three decades later, Burbidge's specimens from Lawas were investigated more closely. Based on 'separate examples' in $\mathrm{K}$ (identified here as K000651484, K000651485, K000651486), and single examples in BM and in Harvard each, $N$. hemsleyana Macfarl. was described as a new species (Macfarlane 1908). Unfortunately, no corresponding specimens are registered today in the databases of BM (http://www.nhm.ac.uk/ research-curation/collections/departmental-collections/botanycollections/search/index.php, last accessed 12 March 2013) and $A$, which now includes all vascular collections at Harvard (http://kiki.huh.harvard.edu/databases/specimen_index.html, last accessed 12 March 2013). In his key to Nepenthes, Macfarlane (1908: 29) contrasts $N$. rafflesiana with $N$. hemsleyana as follows (translated from Latin):

"[B.a.ß.III.] 2. Pitchers sub-distended (subventricosa) to tubulous, cylindrical comb-like peristome very elongated into a neck, edge comb-like, pitcher inside to the middle or below middle glabrous then glandulous $\rightarrow N$. hemsleyana.

[B.a.ß.III.] 3. Pitchers distended (ventricosa) to funnel-shaped, the wide peristome skewed towards the inside, very elongated into a neck, edge comb-like, pitcher inside through the upper quarter or third part glabrous then glandulous $\rightarrow N$. rafflesiana."

In notes to its description, $N$. hemsleyana is portrayed as resembling $N$. rafflesiana "by the long leaf stalk and the elongated comb-like peristome", while being distinct in "the nerves of the leaves, the long and slender tendril, the slim and elongated 
pitchers, the heart-shaped lid with diffused glands, the deep (profunda) off-leading (deducente) surface" (translated from Latin, Macfarlane 1908). The last characteristic is even more elaborate in the description of the upper pitchers as "inside through upper half or deeper waxy (glaucum), darkened (opacum) and leading off (deducens), below shiny (nitidum) glandular and detaining (detinens)". It appears Macfarlane already had a decent understanding of the different biomechanical properties of these surfaces.

Just 20 years later, Danser (1928) reduced N. hemsleyana to a synonym of $N$. rafflesiana. He wrote:

"In the separation of $N$. hemsleyana I can not follow Macfarlane; I have seen specimens that more or less agree with the original description, especially Hallier B 1459 [Oeloe Kenepai, 20.12.1893, located at BO], but I can find no reason to consider them as a distinct species."

Danser did not include K, BM and Harvard in his list of institutions he visited while researching his revision, and for his description of $N$. rafflesiana he only saw one sheet from Burbidge's voyage, a male specimen (s.n.) located at SING. It therefore appears that $N$. hemsleyana was reduced to synonymy without investigation of the type material. Danser specifies the inner surface of upper pitchers of $N$. rafflesiana as wholly glandular, a characteristic clearly not exhibited by at least one of the type specimens of $N$. hemsleyana (K000651485).

In the most recent treatments of the genus Nepenthes, Danser's interpretation of $N$. hemsleyana as belonging to $N$. rafflesiana was continued (Jebb \& Cheek 1997, Cheek \& Jebb 2001).

But especially during the last decade, our knowledge of $\mathrm{Ne}$ penthes in Borneo has greatly improved. As highlighted by Clarke et al. (2011), a number of authors have observed or experimentally demonstrated stable ecological, physiological and morphological differences between two subgroups within the taxon $N$. rafflesiana sensu Danser, comprising different UV reflectance patterns, scent production and capture rate (Moran 1996), the different ontogeny of pitcher morphology (Gaume \& Di Giusto 2009), alternative insect trapping strategies (Bauer et al. 2011), and a mutualistic interaction with bats exclusive for one subgroup (Grafe et al. 2011, Schöner et al. 2013). Although the two subgroups were clearly understood by all of the specialists, the nomenclature used has been informal and inconsistent, until Clarke et al. (2011) resolved this by recognising two separate species, splitting the new taxon $N$. baramensis C.Clarke, J.A.Moran \& Chi.C.Lee from N. rafflesiana.

Independent from all of the work above, $N$. rafflesiana var. subglandulosa J.H.Adam \& Hafiza was described from material collected in northern Sarawak (Adam \& Hamid 2006). It differs from typical $N$. rafflesiana by the presence of a waxy layer on the inside of the upper pitchers, covering the upper fifth of their length. Adam \& Hamid (2006) report another collection belonging to this taxon from Brunei, which appears to be Jacobs 5684, the sheet of which at Kew (K000651487) is labelled as an isotype and with "determinavit: N. rafflesiana var. subglandulosa Adam et Wilcock, J.H. Adam 25.1.1991". Note that in 1991 this name was not yet validly published. Although $N$. rafflesiana var. subglandulosa resembles the informally named plants known from ecological research in Brunei and $N$. baramensis, a relationship between them was not established by any author. Since Clarke et al. (2011) included a duplicate of Jacobs 5684 at Kuching, Sarawak (SAR) in their description of $N$. baramensis, it is evident that both names had been given to the same plant.

Here, we show that the primary morphological difference between $N$. rafflesiana and $N$. hemsleyana, the presence or absence of a waxy zone in upper pitchers, is linked with characteristic shapes and proportions of leaves on climbing stems and rosettes. Thus, we argue that Macfarlane (1908) was correct in treating $N$. hemsleyana as a distinct species, and that the taxa described by Adam \& Hamid (2006) and Clarke et al. (2011) belong to this species. Accordingly, N. baramensis and $N$. rafflesiana var. subglandulosa are recognised as heterotypic synonyms of $N$. hemsleyana, which is reinstated according to the priority rule.

\section{MATERIALS AND METHODS}

Fieldwork to compare leaf proportions was conducted in six different sites in Brunei Darussalam, in the Tutong and Belait Districts. Sixty-four plants of the N. hemsleyana-N. rafflesiana subgroup were assigned to four categories, which correspond to the combinations of two distinct characters with two states each. The first character was status of the waxy zone in upper pitchers (either present or absent), the second character was the plant habit (either ground rosette / lower leaf or climbing vine / upper leaf). For each plant in each of the four categories three variables were established with a measuring tape: leaf width (maximum width of the phyllodium), leaf length (length of the phyllodium) and length of the petiole. Only one fully grown leaf bearing a functional pitcher per clonal plant was used to avoid pseudo replication. The ratios of (a) leaf length to leaf width and (b) leaf length to petiole length were compared among the four categories to address genetic rather than environmental effects on leaf shape. The data did not meet the assumptions of parametric analysis (i.e., normality and homoscedasticity), thus non-parametric comparisons of test statistics were performed. All statistics were done in $R(R$ Development Core Team 2011).

Voucher specimens representing these plants were collected in Brunei Darussalam and will be deposited at $L$ (see Table 1).

Table 1 Voucher specimens.

\begin{tabular}{|c|c|c|c|c|c|}
\hline Collector \& Number & Taxon & Country & Site name & Collection date & Herbarium \\
\hline M. Scharmann 1101 & Nepenthes rafflesiana Jack & Brunei Darussalam & Badas PSF & 14 May 2011 & L \\
\hline M. Scharmann 1102 & Nepenthes hemsleyana Macfarl. & Brunei Darussalam & Badas PSF & 14 May 2011 & L \\
\hline M. Scharmann 1103 & Nepenthes hemsleyana Macfarl. & Brunei Darussalam & Badas Heath / Lumut site & 20 May 2011 & L \\
\hline M. Scharmann 1104 & Nepenthes hemsleyana Macfarl. & Brunei Darussalam & Badas Heath / Lumut site & 21 May 2011 & L \\
\hline M. Scharmann 1105 & Nepenthes ampullaria Jack x Nepenthes hemsleyana Macfarl. & Brunei Darussalam & Badas Heath / Lumut site & 22 May 2011 & L \\
\hline M. Scharmann 1106 & Nepenthes $\mathrm{x}$ hookeriana Lindl. & Brunei Darussalam & Badas Heath / Lumut site & 23 May 2011 & L \\
\hline M. Scharmann 1107 & Nepenthes hemsleyana Macfarl. & Brunei Darussalam & Badas Heath / Lumut site & 24 May 2011 & L \\
\hline M. Scharmann 1108 & Nepenthes hemsleyana Macfarl. & Brunei Darussalam & Badas Heath / Lumut site & 25 May 2011 & L \\
\hline M. Scharmann 1109 & Nepenthes hemsleyana Macfarl. & Brunei Darussalam & Badas Heath / Lumut site & 26 May 2011 & L \\
\hline M. Scharmann 1110 & Nepenthes rafflesiana Jack & Brunei Darussalam & Badas PSF & June 2011 & L \\
\hline M. Scharmann 1111 & Nepenthes rafflesiana Jack & Brunei Darussalam & Badas PSF & June 2011 & L \\
\hline M. Scharmann 1112 & Nepenthes hemsleyana Macfarl. & Brunei Darussalam & Badas PSF & June 2011 & L \\
\hline M. Scharmann 1113 & Nepenthes hemsleyana Macfarl. & Brunei Darussalam & Badas PSF & June 2011 & L \\
\hline
\end{tabular}




\section{Taxonomic treatment}

\section{Nepenthes hemsleyana Macfarl.}

Nepenthes hemsleyana Macfarl. (1908) 61. - Type: Burbidge s.n. (lecto, designated here, K Acc. No. K000651485; iso K Acc. Nos. K000651484 and K000651486), Borneo, Sarawak, Lawas River, 1877. (http://apps. kew.org/herbcat/getImage.do?imageBarcode=K000651484, http://apps. kew.org/herbcat/getlmage.do?imageBarcode=K000651485 and http:// apps.kew.org/herbcat/getImage.do?imageBarcode=K000651486, last accessed 30 May 2012).

Nepenthes rafflesiana Jack var. subglandulosa J.H.Adam \& Hafiza (Adam \& Hamid 2006) 348. - Type: JHA8333 (holo UKMB, n.v.; iso UKMB, n.v.), Sarawak State of Malaysia, Miri, Lambir Hill, along the road to Telekom Malaysia Receiving Station, growing in open vegetation with $N$. gracilis and dominated by thicket of fern Dicranopteris linearis.

Nepenthes baramensis C.Clarke, J.A.Moran \& Chi.C.Lee (2011) 230. — Type: Hotta M. 12419 (SAR, n.v.), Brunei, Belait District, Seria, en route K. Badas to Seria along the railway of B.S.C., 7 Dec. 1963.

Etymology. The specific epithet honours Kew botanist William Botting Hemsley (1843-1924), who described N. macfarlanei Hemsl. in 1905.

Distribution - Borneo: Baram district and Bintulu area of Sarawak, and Belait and Tutong districts of Brunei (Clarke et al. 2011, pers. observ.). Probably more widespread on Borneo, but see discussion below.

Hybrids - In Brunei, N. ampullaria Jack $\times$ hemsleyana (M. Scharmann 1105) and N. hemsleyana $\times$ rafflesiana have been documented, but occur only in habitats resulting from anthropogenic disturbance. The former is distinct from sympatric $N$. $\times$ hookeriana Lindl. (M. Scharmann 1106) in the presence of a waxy zone, hairs on the upper side of the lid (see Table 2) and the narrower peristome.

Note - A very accurate description of $N$. hemsleyana is already available in the description of its heterotypic synonym $N$. baramensis (Clarke et al. 2011). See the same publication for further specimens, informal synonyms, further notes and a table to distinguish it from $N$. rafflesiana. The present study led to the identification of several additional characteristics (Table 2).

\section{RESULTS AND DISCUSSION}

Investigating plants in situ in Brunei, leaf shapes and proportions were found to be different between plants with a waxy zone in upper pitchers (representing $N$. hemsleyana) and those without a waxy zone in upper pitchers (representing $N$. rafflesiana) (Fig. 1). The upper leaves of $N$. rafflesiana were proportionally wider than those of $N$. hemsleyana, while no such difference existed between the lower leaves (Fig. 2a, Kruskal-Wallis test; $\chi^{2}$ $(d f=3, n=64)=28.862 ; p<0.001$; post-hoc paired Wilcoxontests with Bonferroni correction). Furthermore, petioles of upper leaves of $N$. rafflesiana were proportionally longer than those of $N$. hemsleyana, with again no such difference in the lower leaves (Fig. 2b, Kruskal-Wallis test; $X^{2}(d f=3, n=64)=31.230$; $p<0.001$; post-hoc paired Wilcoxon-tests with Bonferroni correction). There was also a significant difference in the ratio of leaf width to petiole length between lower and upper leaves, but this trait was shared by both species (Fig. 2c, Kruskal-Wallis test; $X^{2}(d f=3, n=64)=23.880 ; p<0.001$; post-hoc paired Wilcoxon-tests with Bonferroni correction).

Interpreting these results in terms of developmental changes during the species' ontogeny, it appears that leaves of both $N$. hemsleyana and $N$. rafflesiana become more narrow relative to the petiole length after changing from rosette into climbing phase. However, $N$. rafflesiana leaves become wider relative to length and are borne on a relatively longer petiole, while $N$. hemsleyana does not change these proportions significantly. This finding adds leaf character differences to the differences in pitcher shape ontogeny reported by Gaume \& Di Giusto (2009): while $N$. rafflesiana gradually reduces the extent of the waxy zone during plant development and approaches an ovoid lower pitcher shape, $N$. hemsleyana retains or extends the waxy zone throughout its life and also retains the elongate lower pitcher shape.

We disagree with Macfarlane's opinion that the longitudinal leaf veins ('nerves') are a key difference of $N$. rafflesiana and $N$. hemsleyana. Nepenthes rafflesiana is described with 5 pairs (Macfarlane 1908), 4-5 pairs (Danser 1928) or 3-5 pairs of longitudinal veins (Cheek \& Jebb 2001), while N. hemsleyana resp. its synonyms are described with 4-5 pairs (Macfarlane 1908), 3-5 pairs (Clarke et al. 2011) or 2 pairs (Adam \& Hamid 2006). Furthermore, Macfarlane (1908) describes the veins in $N$. hemsleyana as situated relatively closer to the midrib (our interpretation of his distance measurements), but in our vouchers their relative positions are similar for both species (measure at widest point of leaf). In the vouchers collected for this study, all specimens of $N$. hemsleyana had 3 pairs (15 lower and upper leaves from 7 specimens), while specimens of $N$. rafflesiana had 4-5 (9 lower and upper leaves from 3 specimens). Considering these slight differences, and the inconsistent earlier reports, we conclude that the leaf veins are not a reliable distinctive characteristic.

It is possible that $N$. hemsleyana has a much wider distribution than currently known, since potential habitat (lowland kerangas, peat swamp forest) is widespread on Borneo, or has been so before human alteration. The species might persist around the type locality in the Lawas district of Sarawak, close to the coast and the border to Sabah. However, this area has undergone severe environmental change since the visit by Burbidge in the 1870s. Anderson (1963) notes the occurrence of a unique type

Table 2 Further characteristics that separate $N$. hemsleyana from $N$. rafflesiana, supplementing the characteristics presented in the description of $N$. baramensis (Clarke et al. 2011: Table 2).

\begin{tabular}{ll}
\hline Characteristic & N. hemsleyana \\
\hline Lower leaves & Oblanceolate, acute, leaf apex clearly distinct from tendril,
\end{tabular}
tendril always round, Fig. 1d

Upper leaves

Linear, 3.0-7.3 times as long as wide, $1.4-5.1$ times as long as the petiole, Fig. $1 \mathrm{~b}$

Lids of adult lower pitchers Frequently with 2 or more 5-10 mm long filiform appendages on upper surface, appendages multicellular, positioned towards the posterior lid margin and usually close to the spur, sometimes on the spur, resembling those in juvenile pitchers and $N$. tentaculata Hook.f. (present in M. Scharmann Nos. 1104, 1107, 1108, 1112)

Colour of leaves in closed Dark green, reddish forest (peat swamp and kerangas)

\section{N. rafflesiana}

Oblanceolate, acuminate or leaf apex ambiguous, tendril frequently flattened/winged, tendril wings continuously merging into leaf margins and the pitcher wings, Fig. 1c (extremely broad tendril wings: described as $N$. rafflesiana var. alata J.H.Adam \& Wilcock)

Oblong, 2.2-4.6 times as long as wide, $1.7-2.8$ times as long as the petiole, Fig. 1a

Never with such filiform appendages 


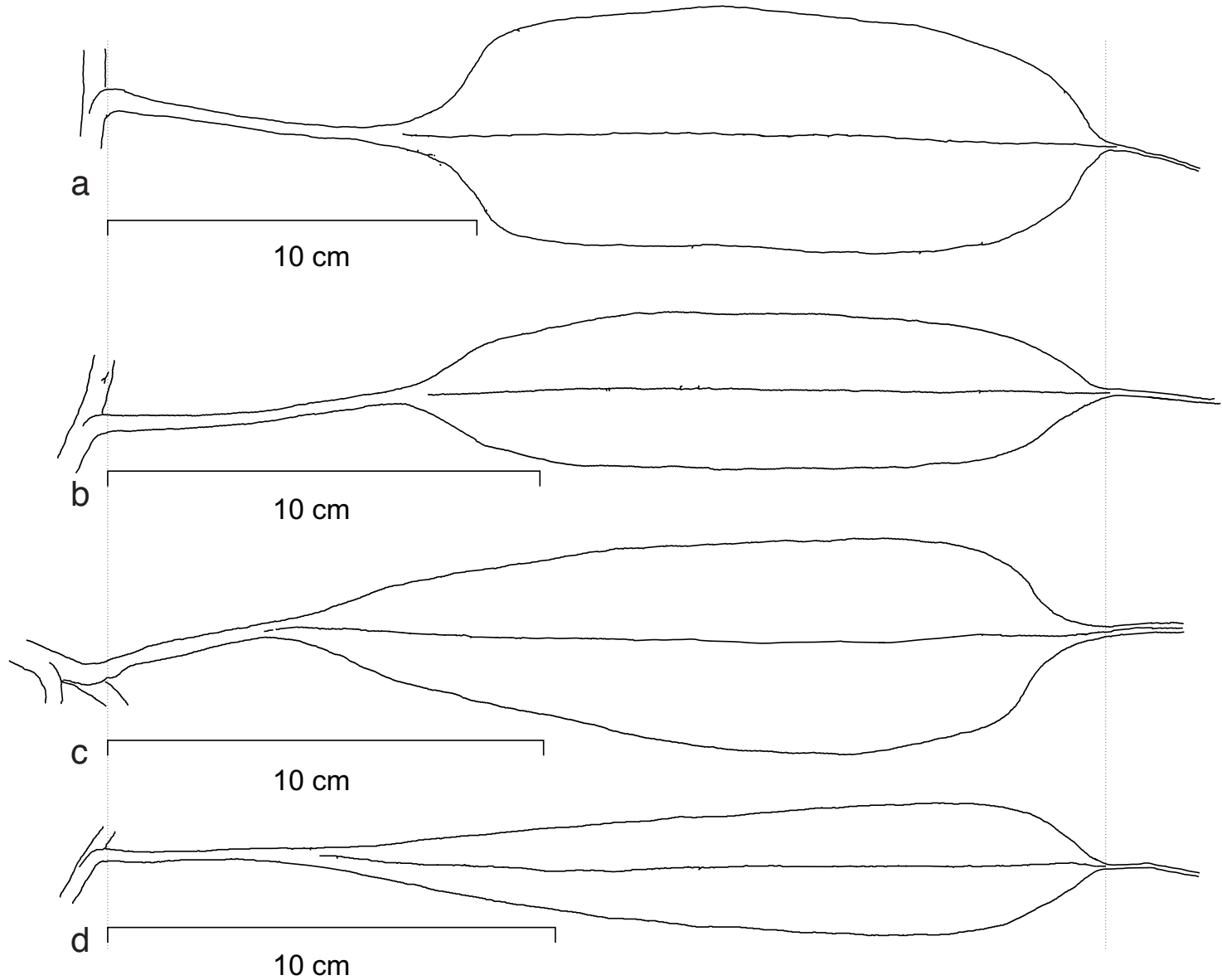

Fig. 1 Characteristic shape of upper and lower leaves. a. N rafflesiana upper leaf; b. N. hemsleyana upper leaf; c. N. rafflesiana lower leaf; d. N. hemsleyana lower leaf. Drawn from dried material (M. Scharmann 1110, 1111, 1112, 1113, plants growing in close proximity), scaled to the same length of petiole plus leaf.

of peat swamp, dominated by species of Dacrydium and Casuarina. Yet already in the 1960s little of this remained. Inspection of satellite imagery (Google Earth, Google Inc; image cover partly dated 4 July 2007, partly undated) and a personal visit to the locality in 2011 showed that almost all forest has been cleared and replaced by oil palm plantations. There are two hills close to the Merapok River that could correspond to the one Burbidge climbed (Burbidge 1880). Both of them have been logged, while the steeper one is partly ablated as a sand quarry and the vegetation heavily degraded by burning. Nepenthes hemsleyana could not be located, but might survive in small pockets of natural vegetation in the general area.
Danser (1928) mentioned the unusual deviation of Hallier B 1459 (see above, collected from the Kenepai River, a tributary of the Kapuas in West Kalimantan, C. N0 ${ }^{\circ} 38^{\prime} \mathrm{E} 111^{\circ} 48^{\prime}$ ) from the description of $N$. rafflesiana. A re-examination of this material at $\mathrm{BO}$ is needed to clarify whether it represents $N$. hemsleyana. Furthermore, photos showing plants with pitchers superficially resembling the species but with extremely narrow phyllodia have appeared from the Kapuas (http://tanamanbuas.proboards.com/index.cgi?board=habitat\&action=display\&thread $=2866$ \& page $=2$, accessed 30 May 2012). $\square$ no waxy zone in upper pitchers (N. rafflesiana) waxy zone in upper pitchers present (N. hemsleyana)
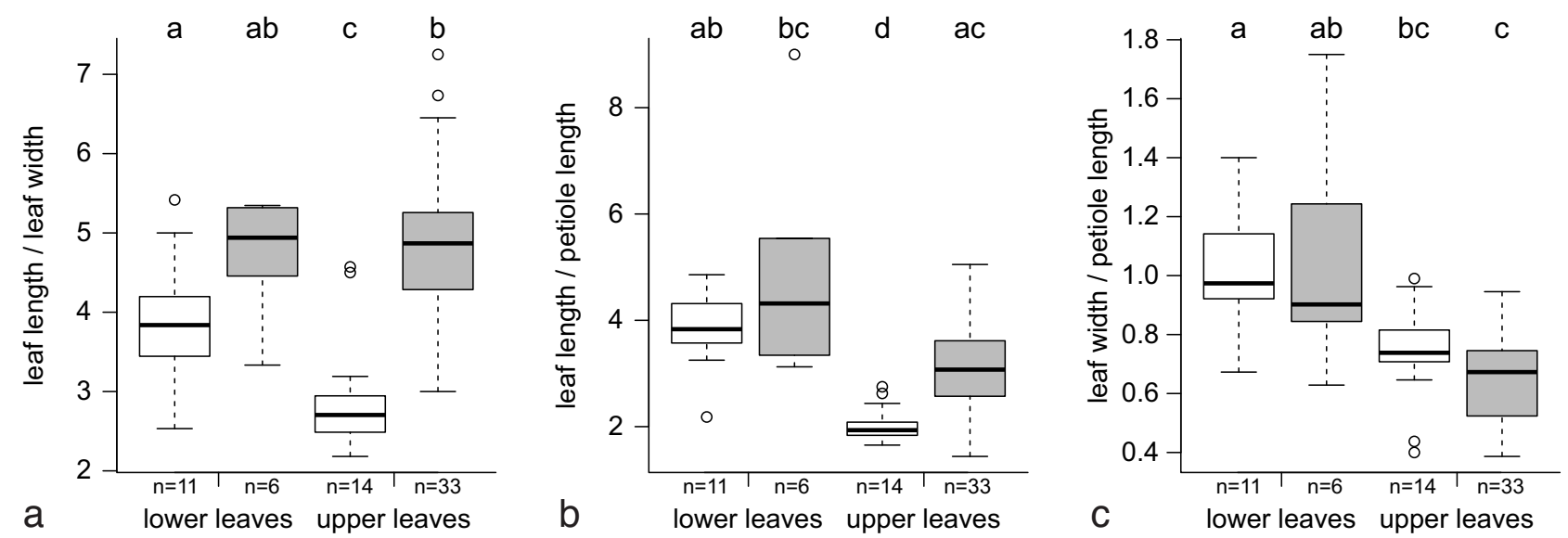

Fig. 2 Leaf proportions of $N$. hemsleyana and $N$. rafflesiana. a. Ratio of leaf length to leaf width; b. ratio of leaf length to petiole length; c. ratio of leaf width to petiole length. Box-whisker plots based on the median, quartiles and extremes within quartile plus $1.5 \times$ IQR, outliers shown as dots. The small letters above data illustrate a significant difference (letter not shared) resp. similarity (letter shared) between groups, resulting from multiple paired comparisons (statistics see text). 
Regarding the practical application of this study, we emphasise that $N$. hemsleyana tend to have relatively narrower leaves with relatively shorter petioles than $N$. rafflesiana (both lower and upper leaves), although absolute length and width as well as the ratios do overlap and are therefore non-exclusive. However, by examining this characteristic in combination with leaf shape (Fig. 1), leaf colouration, tendril insertion and presence of lid hairs on lower pitchers (Table 2), N. hemsleyana and N. rafflesiana can usually be separated in the field even when upper pitchers are unavailable, particularly when directly compared in the same habitat.

To conclude, the taxonomic separation of $N$. hemsleyana and $N$. rafflesiana is justified by their different pitcher and leaf morphology, and consequently by divergent physiology and ecology. Although they often grow in close proximity to one another and share many traits, some traits are not randomly combined but linked (e.g. waxy zone in upper pitchers with narrower leaves), indicating a certain degree of reproductive isolation between the two taxa.

Acknowledgements The authors thank the family of Abdul Hadzid Harith Tinggal and leney Daud (Telamba Homestay), as well as Yen Shan Lim and family, for their help and support in all logistical matters in Brunei. Walter Federle, Daniel G. Thornham and Joanna M. Smith are thanked for assistance in the field and beyond. Charles Clarke, D.G. Thornham and two anonymous reviewers gave helpful comments on the manuscript. The work in Brunei Darussalam was conducted under research permit UBD/ PSR/5.1 and Nepenthes samples were exported under CITES permit No. BA/MAP/191/1108. Funding was provided by a grant from the Leverhulme Trust (F/09 364/G) and a DAAD stipend to M.S.

\section{REFERENCES}

Adam JH, Hamid HA. 2006. Pitcher plants of Lambir Hill in Miri, Sarawak State of Malaysia. International Journal of Botany 2: 340-352. doi: 10.3923/ ijb.2006.340.352.

Anderson JAR. 1963. The flora of the Peat Swamp Forests of Sarawak and Brunei, including a catalogue of all recorded species of flowering plants, ferns and fern allies. Gardens' Bulletin Singapore 20, 2: 131-228.

Bauer U, Grafe TU, Federle W. 2011. Evidence for alternative trapping strategies in two forms of the pitcher plant, Nepenthes rafflesiana. Journal of Experimental Botany 62, 10: 3683-3692. doi: 10.1093/Jxb/Err082.

Burbidge FW. 1880. The gardens of the sun. Murray, London.

Cheek MR, Jebb MHP. 2001. Nepenthaceae. Flora Malesiana, Ser. I, 15: $1-157$.

Clarke C, Moran JA. 2011. Incorporating ecological context: a revised protocol for the preservation of Nepenthes pitcher plant specimens (Nepenthaceae). Blumea 56: 225-228. doi: 10.3767/000651911x605781.

Clarke C, Moran JA, Lee CC. 2011. Nepenthes baramensis (Nepenthaceae) - a new species from north-western Borneo. Blumea 56: 229-233. doi: 10.3767/000651911x607121.

Danser BH. 1928. The Nepenthaceae of the Netherlands Indies. Bulletin du Jardin Botanique de Buitenzorg, Série III, 9, 3-4: 249-438.

Gaume L, Di Giusto B. 2009. Adaptive significance and ontogenetic variability of the waxy zone in Nepenthes rafflesiana. Annals of Botany 104 , 7: 1281-1291. doi: 10.1093/Aob/Mcp238.

Grafe TU, Schöner CR, Kerth G, Junaidi A, Schöner MG. 2011. A novel resource-service mutualism between bats and pitcher plants. Biology Letters 7, 3: 436-439.

Hooker JD. 1873. Nepenthaceae. In: De Candolle A (ed), Prodromus Systematis Naturalis Regni Vegetabilis. Vol. 17: 90-105.

Jebb MHP, Cheek MR. 1997. A skeletal revision of Nepenthes (Nepenthaceae). Blumea 42: 1-106.

Macfarlane JM. 1908. Nepenthaceae. In: Engler A (ed), Das Pflanzenreich IV.III: 1-91. Engelmann, Leipzig.

Moran JA. 1996. Pitcher dimorphism, prey composition and the mechanisms of prey attraction in the pitcher plant Nepenthes rafflesiana in Borneo. Journal of Ecology 84, 4: 515-525.

R Development Core Team. 2011. R: A language and environment for statistical computing. R Foundation for Statistical Computing, Vienna, Austria.

Schöner CR, Schöner MG, Kerth G, Grafe TU. 2013. Supply determines demand: influence of partner quality and quantity on the interactions between bats and pitcher plants. Oecologia, in press, published online: doi: 10.1007/s00442-013-2615-x.

Thiers B. [Continuously updated]. Index Herbariorum: A global directory of public herbaria and associated staff. New York Botanical Garden's Virtual Herbarium. http://sweetgum.nybg.org/ih/.

Van Steenis-Kruseman MJ, Van Welzen PC. [1950 onwards]. Cyclopaedia of Malesian collectors. Retrieved 18.06.2012, from Nationaal Herbarium Nederland. www.nationaalherbarium.nl/fmcollectors/B/BurbidgeFW.htm. 